\title{
Evaluation of the 'Hedgehog' signaling pathways in squamous and basal cell carcinomas of the eyelids and conjunctiva
}

\author{
ALI RIZA CENK CELEBI ${ }^{1}$, HAYYAM KIRATLI ${ }^{2}$ and FIGEN SOYLEMEZOGLU ${ }^{3}$ \\ ${ }^{1}$ Department of Ophthalmology, Acibadem University School of Medicine, 34303 Istanbul; \\ Departments of ${ }^{2}$ Ophthalmology and ${ }^{3}$ Pathology, Hacettepe University School of Medicine, 06100 Ankara, Turkey
}

Received July 24, 2015; Accepted May 10, 2016

DOI: $10.3892 / 01.2016 .4625$

\begin{abstract}
The purpose of the present study was to assess the role of hedgehog signaling pathway in the carcinogenesis of eyelid skin and conjunctival epithelial malignant tumors. The study was conducted on specimens from 41 patients with cutaneous eyelid basal cell carcinoma, 22 with bulbar conjunctival squamous cell carcinoma, 12 with bulbar conjunctival intraepithelial neoplasia. Major molecules of Hedgehog signaling pathway (Sonic Hedgehog [Shh] and Patched-1 [Ptch-1] and Glioma-associated oncogene [Gli-1]) were evaluated in paraffin-embedded tissue specimens using immunohistochemical staining. For each specimen, the percentage $(<10 \%, 10-50 \%,>50 \%)$ and the intensity of the immunohistochemical staining (graded from 0 to 3 ) were calculated and the scores obtained by multiplication of two values were analyzed using the Kruskall-Wallis test. Shh and Ptch-1 expression levels were statistically significantly lower in the basal cell carcinoma group compared with the squamous cell carcinoma group $(\mathrm{P}=0.043$ for $\mathrm{Shh} ; \mathrm{P}=0.030$ for $\mathrm{Ptch}-1)$. In the conjunctival squamous cell carcinoma group, the Ptch-1 score was 0 in $\sim 25 \%$ of specimens and the Gli-1 score was $\leq 2$ in $\sim 45 \%$ of cases. In the conjunctival intraepithelial neoplasia group, the Ptch-1 score was $\geq 2$ in $66 \%$ of specimens, the Gli-1 score was $\leq 2$ in $\sim 92 \%$ of cases. Ptch- 1 mutations contribute to the development of cutaneous eyelid basal cell carcinoma. The present study provides evidence that alterations in hedgehog signaling pathways may lead to transformation of the conjunctival intraepithelial neoplasia into invasive squamous cell carcinoma.
\end{abstract}

Correspondence to: Dr Ali Riza Cenk Celebi, Department of Ophthalmology, Acibadem University School of Medicine, 16 Turgut Ozal Boulevard, Kucukcekmece, 34303 Istanbul, Turkey

E-mail: arcenkcelebi@gmail.com

Key words: conjunctival intraepithelial neoplasia, glioma-associated oncogene-1 protein, patched-1 protein, periocular skin cancers, sonic hedgehog protein

\section{Introduction}

Basal cell carcinoma (BCC) is the most common type of periocular cancer in human (1). The epidermis originates from basal cell exchange, the infindibular cells of hair follicles or from pluripotent stem cells and this may explain why BCC does not develop from any precursor lesions $(2,3)$. Squamous cell cancer (SCC) is the second most common tumor of the eyelids $(1,4)$. Although the exact mechanism in SCC pathogenesis is unknown, environmental and internal stimulus and interruption of control mechanisms that enable growth and regulation are considered as the main causes of tumorigenesis (5). Ocular surface squamous neoplasia constitutes $14 \%$ of the eye tumors (6). Ocular surface squamous neoplasia develops with the disruption in DNA repair mechanisms as a result of somatic mutation caused by UV-B irradiation. Ocular surface squamous neoplasia tends to start at the limbus because of the preferential location of the stem cells (6). According to the stem cell theory, external factors and tissue changes due to changing conditions in this anatomical region disrupt the mechanism of stem cells and lead to the development of abnormal epithelium giving rise to squamous neoplasia (6).

Any event disrupting the self-renewal process of stem cell may result in the initiation of carcinogenesis (7). Various signal transduction pathways take part in self-renewal and repair of skin stem cells: These signaling pathways are Wnt, Notch, TGF $\beta$, EGF, FGF, IGF, hedgehog systems and their secretory products (8). In the misregulation of Hedgehog pathway, cell self-renewal cycle fails and tumorigenesis is initiated (9). Sonic Hedgehog (Shh) is a crucial morphogen for proper cellular proliferation in the development of mammals (10). Shh provides cell proliferation by cell to cell communication, regulation of cell death, ensuring continuity of stem cells, and plays role in stem cell self-renewal process in hematopoietic system, skin, nervous system and breast tissue (11). In this pathway, Shh, Indian Hedgehog (Ihh), or Desert Hedgehog (Dhh) are secreted ligands; and Patched-1 (PTCH1) and Patched-2 (PTCH2) are receptors of those ligands. $\mathrm{SHH}$ is one of the most studied and well-known protein ligands among the important proteins of hedgehog signaling pathway. Disruptions in the Shh pathway has an effective role in the abnormal development of stem cells. Shh signaling is increased in epidermal tumors $(12,13)$ and 
an increase in Shh signaling is responsible for brain, skin, muscle, small cell lung, gastrointestinal tract, prostate, breast and pancreatic cancer (14). PTCH-1 is a protein product of a tumor suppressor gene, directly connected to the early steps of tumor formation process (15). Ptch-1 protein acts as a receptor for Shh family signaling molecules (15). Ptch-1 inactivation is responsible for basal cell nevus syndrome (16). The PTCH gene is mutated in sporadic BCC (PTCH-1) and certain medulloblastomas (PTCH-2) with rhabdomyomas and rhabdomyosarcomas $(15,17,18)$. Gli-1 is one of the zinc finger proteins. Excessive activation of Gli-1 has been associated with the development of BCC $(19,20)$. Smo is the Gli activator under the suppression of Ptch. In the presence of Shh ligands, suppression of Ptch on Smo ends. Smo, in this case causes cytoplasmic Gli transcription factors to enter the nucleus and these factors stimulate the increase in the expression of proteins required for cell proliferation (11). The interactions between these molecules are presented in Fig. 1.

In the present retrospective study, the levels of Shh over-expression were investigated in human bulbar conjunctival SCC, bulbar conjunctival in situ carcinoma, BCC of the cutaneous eyelid paraffin tissue blocks by using immunohistochemistry.

\section{Materials and methods}

Samples. The study protocol was approved by the Hacettepe University Faculty of Medicine Medical Researches Local Ethics Committee and was performed in accordance with the Declaration of Helsinki. Each patient provided written informed consent for the publication of the study. In this study, clinicopathological records of patients with bulbar conjunctival invasive SCC, bulbar conjunctival in-situ cancer and cutaneous eyelid BCC were reviewed from the Ocular Oncology Unit, Department of Ophthalmology (Hacettepe University School of Medicine, Ankara, Turkey). The 3 groups included: Bulbar conjunctival SCC group, 10 men and 12 women aged between 15-83 years (mean: 61.27 years); a bulbar conjunctival carcinoma in situ group, 9 men, 3 women, aged between 8-75 years (mean: 58.9 years); and a cutaneous eyelid BCC group, 23 men, 18 women aged between 29-78 years (mean: 60.7 years) were included. No differences were observed between groups regarding age and gender (ANOVA, $\mathrm{P}>0.05$ ).

Immunohistochemistry (IHC). Indirect IHC was performed between January 1, 1998 and January 1, 2009 in the following samples: 22 cross-sections were diagnosed with bulbar conjunctival invasive SCC, 12 cross-sections were diagnosed of bulbar conjunctival carcinoma in situ and 41 cross-sections were diagnosed with cutaneous eyelid BCC. Sections were incubated with SHH primary antibody (AB73958; Abcam Biotechnology, Cambridge, Massachusetts, USA; 1:100 dilution) and cytoplasmic/membranous staining on human lung tissue was regarded as a positive control. Sections were incubated with PTCH-1 primary antibody (AB53715; Abcam Biotechnology; 1:100 dilution) and cytoplasmic/membranous staining on human brain tissue was regarded as a positive control. Citrate pre-processing antibody solution prepared in $1 / 100$ concentra-

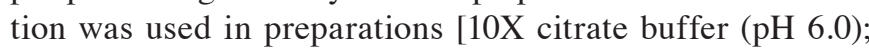
catalog no. AB64214; Abcam Biotechnology). Sections were

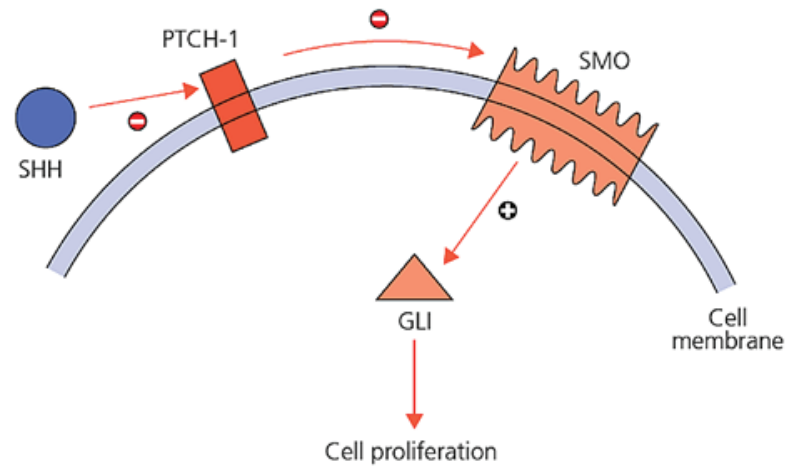

Figure 1. Interactions between Shh, Ptch-1 and Gli-1.

incubated with GLI-1 primary antibody (SC20687; Santa Cruz Biotechnology Santa Cruz, California, USA). Nuclear staining on seminiferous canal and cytoplasmic staining on Leydig cell were regarded as a positive control. EDTA pre-processing antibody solution prepared in $1 / 100$ concentration was used in preparations. Subsequent to being washed twice in phosphate-buffered saline (PBS; 20X PBS Buffer with Tween 20; catalog no. AB64028; Abcam Biotechnology), for 5 min each, the sections were incubated with the secondary antibody, anti-rabbit IgG VHH Single Domain-HRP, at a $0.1 \mu \mathrm{g} / \mathrm{ml}$ concentration (catalog no. AB191866; Abcam Biotechnology) for $30 \mathrm{~min}$ at room temperature. Subsequent to being washed twice in PBS, for 5 min each, color development was assessed in the sections using DAB chromogen (DAB Substrate kit; catalog no. AB64238; Abcam Biotechnology) and a hematoxylin counterstain.

Scoring. Bulbar conjunctival invasive SCC, bulbar conjunctival in-situ cancer and BCC of the eyelid have been reviewed by a professional neuro-ophthalmic pathology professor. The scores obtained from multiplying tumor percentage and dye intensity were used in statistical evaluation. The percentage of tumor dyed by primary antibody was $100 \%$ in all of tumor area. This process was performed by separating the specimen slides into three groups $(<10 \%, 10-50 \%,>50 \%)$ under $4 x$ or 10x magnification of microscope. The preparations with $<10 \%$ received 1 , those that scored between $10-50 \%$ were designated 2 and those with $>50 \%$ received 3 points, respectively. Dye intensity was expressed as weak, medium and strong. Weak staining was used for preparation with only selectable staining pattern of primary antibody under 40x magnification of microscope and got 1 point. Moderately stained preparations were used for preparations with selectable staining pattern of primary antibody under $20 x$ magnification of microscope and got 2 points. Strong staining was only used for preparation with selectable staining pattern of primary antibody under 10x magnification of microscope and got 3 points (Fig. 2).

Statistical analysis. Data entry was performed using SPSS version 11.5 (SPSS, Inc., Chicago, IL, USA), and an analysis of variance and Kruskall-Wallis test were used for significance testing of the differences between the three groups, as the data showed an ordered sequence. $\mathrm{P}<0.05$ was used to indicate a statistically significant difference. 
Table I. Shh, Ptch-1 and Gli-1 dye intensity in cancer groups.

\begin{tabular}{|c|c|c|c|c|c|c|c|c|c|c|c|c|}
\hline \multirow{2}{*}{$\begin{array}{l}\text { Antibody type } \\
\text { Intensity/Tumor group }\end{array}$} & \multicolumn{4}{|c|}{ Shh } & \multicolumn{4}{|c|}{ Ptch-1 } & \multicolumn{4}{|c|}{ Gli-1 } \\
\hline & 0 & $1+$ & $2+$ & $3+$ & 0 & $1+$ & $2+$ & $3+$ & 0 & $1+$ & $2+$ & $3+$ \\
\hline Lid+conjunctiva SCC & 8 & 8 & 5 & 1 & 6 & 12 & 3 & 1 & 7 & 5 & 8 & 2 \\
\hline Conjunctival in situ cancer & 3 & 3 & 5 & 1 & 4 & 3 & 5 & 0 & 4 & 7 & 1 & 0 \\
\hline Lid BCC & 21 & 16 & 2 & 2 & 18 & 19 & 4 & 0 & 8 & 15 & 13 & 5 \\
\hline
\end{tabular}

Shh, Sonic hedgehog protein; Gli-1, Glioma-associated oncogene-1 protein: Ptch-1, Patched-1 protein, SCC, squamous cell carcinoma; BCC, basal cell carcinoma.

Table II. Shh, Ptch-1, Gli-1 staining percentage in cancer groups.

\begin{tabular}{|c|c|c|c|c|c|c|c|c|c|}
\hline Antibody type & \multicolumn{3}{|c|}{ Shh } & \multicolumn{3}{|c|}{ Ptch-1 } & \multicolumn{3}{|c|}{ Gli-1 } \\
\hline Tumor percentage/Tumor group & $<10$ & $10-50$ & $>50$ & $<10$ & $10-50$ & $>50$ & $<10$ & $10-50$ & $>50$ \\
\hline Lid+conjunctival SCC & 14 & 8 & 0 & 9 & 11 & 2 & 10 & 9 & 3 \\
\hline Conjunctival in situ cancer & 6 & 6 & 0 & 4 & 6 & 2 & 7 & 5 & 0 \\
\hline Lid BCC & 33 & 8 & 0 & 25 & 15 & 1 & 13 & 18 & 10 \\
\hline
\end{tabular}

Shh, Sonic hedgehog protein; Gli-1, Glioma-associated oncogene-1 protein: Ptch-1, Patched-1 protein, SCC, squamous cell carcinoma; BCC, basal cell carcinoma.

Table III. Shh, Ptch-1 and Gli-1 score distribution in cancer groups.

\begin{tabular}{|c|c|c|c|c|c|c|c|}
\hline Score/Tumor group & 0 & 1 & 2 & 4 & 6 & 9 & Total \\
\hline \multicolumn{8}{|l|}{ Shh SCORES } \\
\hline Lid+conjunctival SCC & 8 & 5 & 4 & 4 & 1 & 0 & 22 \\
\hline Conjunctival in situ cancer & 3 & 3 & 0 & 5 & 1 & 0 & 12 \\
\hline Lid BCC & 21 & 11 & 6 & 1 & 2 & 0 & 41 \\
\hline \multicolumn{8}{|l|}{ Ptch-1 SCORES } \\
\hline Lid+conjunctival SCC & 6 & 3 & 9 & 2 & 2 & 0 & 22 \\
\hline Conjunctival in situ cancer & 4 & 0 & 3 & 3 & 2 & 0 & 12 \\
\hline Lid BCC & 18 & 7 & 12 & 3 & 1 & 0 & 41 \\
\hline \multicolumn{8}{|l|}{ Gli-1 SCORES } \\
\hline Lid+conjunctival SCC & 7 & 3 & 2 & 6 & 3 & 1 & 22 \\
\hline Conjunctival in situ cancer & 4 & 3 & 4 & 1 & 0 & 0 & 12 \\
\hline Lid BCC & 8 & 5 & 10 & 7 & 7 & 4 & 41 \\
\hline
\end{tabular}

Shh, Sonic hedgehog protein; Gli-1, Glioma-associated oncogene-1 protein: Ptch-1, Patched-1 protein, SCC, squamous cell carcinoma; BCC, basal cell carcinoma.

\section{Results}

SHH dye intensity distribution of the 3 cancer groups (bulbar conjunctival SCC, bulbar conjunctival carcinoma in situ and cutaneous eyelid BCC) are summarized in Table I and differences in the negative staining between the 3 cancer groups were statistically significant $(\mathrm{P}=0.043)$. $\mathrm{PTCH}$ dye intensity distribution of every 3 cancer groups are summarized in Table I and no significant difference was observed for the negative staining between the 3 cancer groups $(\mathrm{P}=0.170)$. However, weak staining in BCC group is noteworthy. Distribution of GLI-1 dye intensity in the 3 cancer groups are summarized in Table I and the negative staining betwen the 3 cancer groups did not show any statistically significant differences $(\mathrm{P}=0.135)$. The percentage of $\mathrm{SHH}$ staining in cancer groups are presented in Table II. Staining $>50 \%$ was not observed in any groups. The difference between negative and total number of positive cases in terms of the SHH scores 

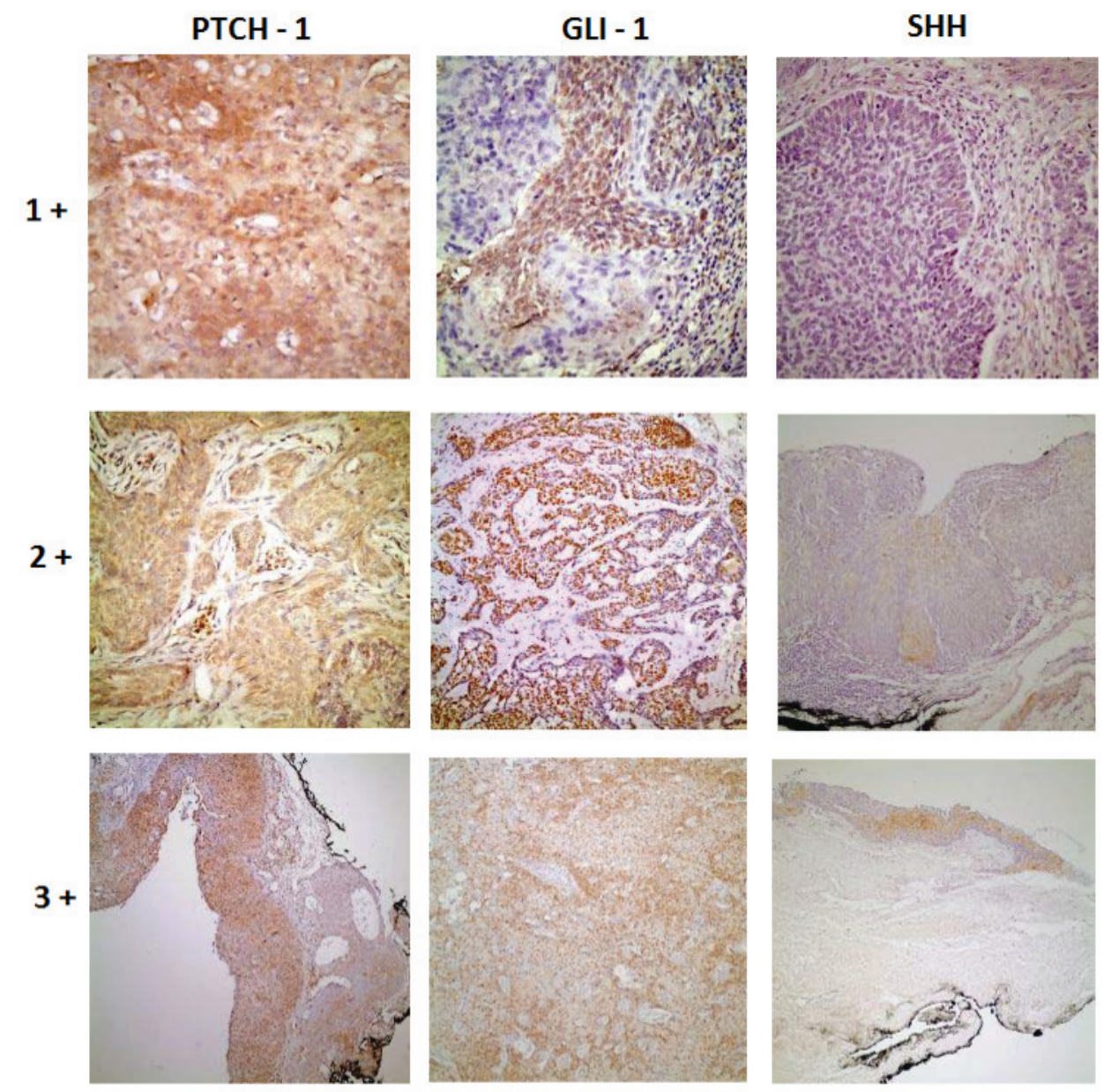

Figure 2. Histopathological view of samples demonstrating how antibodies dye intensities were assessed (stain, DAB; +1 , magnification, $40 ;+2$, magnification, $\mathrm{x} 20 ;+3$, magnification, x10). Shh, Sonic hedgehog protein; Gli-1, Glioma-associated oncogene-1 protein: Ptch-1, Patched-1 protein.

did not demonstrate any significant differences between the tumor groups $(\mathrm{P}=0.182)$, but in general, $\mathrm{SHH}$ scores were generally low in all groups. Differences in negative and total number of positive cases in terms of PTCH-1 score between the tumor groups demonstrated statistically significant differences $(\mathrm{P}=0.030)$. The difference between negative and total number of positive cases in terms of GLI-1 scores did not change significantly among tumor groups $(\mathrm{P}=0.064)$, but GLI-1 scores in BCC group had higher scores compared with the other tumor types (Table III).

\section{Discussion}

When the hedgehog signaling pathway is over-activated, the self-renewal cell cycle fails and the tumor formation process is initiated (9,21-24). An increase in Shh signaling is responsible for the development of brain, skin, muscle, small cell lung, gastrointestinal tract, prostate, breast and pancreatic cancers (14). Tojo et al (24) studied 19 nodular and 6 superficial sporadic BCC, and demonstrated that in superficial BCC Ptch mRNA expression was in a level that could not be identified with in situ hybridization method and they also predicted that it was associated with invasion of dermis. In the present study, the low Ptch-1 expression score in the BCC group was found to be statistically significant and this evidence also supports the evidence that Ptch-1 mutations may serve a role in the development of sporadic BCC, hypothesized by Kim et al (25). In the present study, Ptch-1 score regarded as the final protein product of mutated Ptch-1 gene, was zero (0) in 18/41 ( 40\%) patients as assessed by IHC. This may mean that mutation occurred in these cases. De Grujil et al (26) suggested that UV radiation may result in Ptch-1 mutations and long-term effects of UV radiation on the development of BCC may also be effective through Ptch-1 mutation. In the present study, UV radiation may be responsible for the 18/41 ( 40\%) patients in which the Ptch-1 score was 0. In 5 BCC cases where exenteration was performed, the Ptch-1 score was $\leq 2$ and this also supports the idea that Ptch-1 mutation may contribute to BCC development. However, this mutation needs to be verified using RNA in situ hybridization methods in further studies. In a previous study on sporadic BCC conducted by Holikova et al (27), Ptch-1 mutations were identified with increased inactive Ptch-1 mRNA in cytoplasm by in situ hybridization method and this was detected in particular in the outer tumor layers with palisade formation; increase of Gli-1 activity was also observed in tumor areas. The authors pointed out that Ptch-1 mutation increases Shh signaling, initiating cell proliferation through the Gli family of transcriptional factors (25). In the present study, $18(7+7+4) / 41(\sim \% 45)$ patients were detected with Gli-1 score $\geq 4$, and a nuclear increase was shown using 
the IHC method. In a study conducted by Green et al (28), an increase in Gli-1 nuclear transcription factors was shown to have an important role in the development of BCC. Lupi showed BCC development after just a single somatic mutation through the Shh pathway and suggested that Ptch-1 mutation was responsible for the development of sporadic and hereditary BCC (29). Decreased Shh intensity in the BCC group was found to be statistically significant in the present study. SHH staining was not observed in 21 of our 41 patients.

In the present study, 6/22 ( 25\%) of patients in SCC group had Ptch-1 score as (0), and were not found to be supportive of SCC development on SHH pathway. However, Xuan et al (30) have demonstrated that hedgehog signaling increases together with HPV-16 infection in uterine cervical squamous carcinoma. The authors highlighted that $95 \%$ of cervical squamous carcinomas demonstrated an increase in Shh expression. The authors also emphasized that the level of Shh expression increased in parallel with frequency of lymph node metastasis (30). In the present study, the SCC group expressed lower levels of Shh and these patients did not have lymph node metastases, suggesting that an increase in Shh expression may be a more effective clue for advanced and metastatic SCC. In another study carried out by Xuan et al (31), approximately twofold increase in Shh expression was observed in transition from intraepithelial lesion to invasive uterine cervical squamous cell carcinoma. In a recent study by Cavicchioli Buim et al (32), low levels of GLI-1 were observed in non-neoplastic oral mucosal squamous epithelial line that was adjacent to the tumor. All oral squamous cell carcinoma cases in this study expressed high levels of Gli-1. Another study by Nishimaki et al (33) demonstrated overexpression of Shh in 5 cell lines among 14 human oral squamous cell carcinoma cell lines. In the present study, the Shh score of 6/12 (50\%) patients suffering from in situ squamous cell carcinoma was $\geq 4$. Again, Gli-1 score of 11 patients in the in situ squamous cell group was $\leq 2$ and Shh increase was not enough on its own in the process of transition from in situ cancer to invasion; and increase was necessary in Gli-1 transcription factor, which is the final effector of hedgehog signaling pathway. In 22 patients in the SCC group, the Ptch-1 score was 0 (zero) in $6(\sim \% 25)$ patients, the Gli-1 score was $\geq 4$ in $10(66 \%)$ patients. In 12 patients in the in-situ cancer group, Ptch-1 score was $\geq 2$ in $8(66 \%)$ patients. Of all the patients in the in-situ cancer group Gli-1 score was $\leq 4$ or fewer. This suggests that in the conversion process from in situ cancer to invasive SCC, hedgehog signaling may take an active role.

The present study present evidence that Ptch-1 mutations contribute to the development of cutaneous eyelid basal cell carcinoma. Alterations in hedgehog signaling pathways may lead to transformation of the conjunctival intraepithelial neoplasia into invasive squamous cell carcinoma. The use of more comprehensive in situ hybridization techniques in addition to IHC method may aid in demonstrating the effect of hedgehog signaling in the pathogenesis of BCC and SCC.

\section{Acknowledgements}

The present study was supported by Hacettepe University The Scientific Research and Development Office. In addition, this study was presented at the $15^{\text {th }}$ biannual meeting of the International Society of Ocular Oncology (ISOO), November 14-17, 2011, Buenos Aires, Argentina.

\section{References}

1. M Rosner: Section 2 eyelid tumors basal cell carcinoma. In: Clinical Ophthalmic Oncology. Singh AD, Damato BE, Murphree AL, Perry JD (eds.) Saunders, Elsevier, Philadelphia, USA, pp76-80, 2007.

2. Margo CE and Waltz K: Basal cell carcinoma of the eyelid and periocular skin. Surv Ophthalmol 38: 169-192, 1993.

3. Allali J, D'Hermies F and Renard G: Basal cell carcinomas of the eyelids. Ophthalmologica 219: 57-71, 2005.

4. Green A: Changing patterns in incidence of non-melanoma skin cancer. Epithelial Cell Biol 1: 47-51, 1992.

5. Donaldson MJ, Sullivan TJ, Whitehead KJ and Williamson RM: Squamous cell carcinoma of the eyelids. Br J Ophthalmol 86: 1161-1165, 2002.

6. Lee GA and Hirst LW: Ocular surface squamous neoplasia. Surv Ophthalmol 39: 429-450, 1995.

7. Tumbar T, Guasch G, Greco V, Blanpain C, Lowry WE, Rendl M and Fuchs E: Defining the epithelial stem cell niche in skin. Science 303: 359-363, 2004.

8. Molofsky AV, Pardal R and Morrison SJ: Diverse mechanisms regulate stem cell self-renewal. Curr Opin Cell Biol1 6: 700-707, 2004.

9. Evangelista M, Tian H and de Sauvage FJ: The hedgehog signaling pathway in cancer. Clin Cancer Res 12: 5924-5928, 2006.

10. Guerrero I and Ruiz i Altaba A: Development: Longing for ligand: Hedgehog, patched, and cell death. Science 301: 774-776, 2003.

11. Toftgård R: Hedgehog signalling in cancer: Cell Mol Life Sci 57: 1720-1731, 2000.

12. Hutchin ME, Kariapper MS, Grachtchouk M, Wang A, Wei L, Cummings D, Liu J, Michael LE, Glick A and Dlugosz AA: Sustained Hedgehog signaling is required for basal cell carcinoma proliferation and survival: Conditional skin tumorigenesis recapitulates the hair growth cycle. Genes Dev 19: 214-223, 2005

13. Owens DM and Watt FM: Contribution of stem cells and differentiated cells to epidermal tumors. Nat Rev Cancer 3: 444-451, 2003.

14. Ruiz A, Altaba I, Stecca B and Sánchez P: Hedgehog-Gli signaling in brain tumors: Stem cells and paradevelopmental programs in cancer. Cancer Lett 204: 145-157, 2004.

15. Wolter M, Reifenberger J, Sommer C, Ruzicka T and Reifenberger G: Mutations in the human homologue of the Drosophila segment polarity gene patched $(\mathrm{PTCH})$ in sporadic basal cell carcinomas of the skin and primitive neuroectodermal tumors of the central nervous system. Cancer Res 57: 2581-2585, 1997.

16. Chidambaram A, Goldstein AM, Gailani MR, Gerrard B, Bale SJ, DiGiovanna JJ, Bale AE and Dean M: Mutations in the human homologue of the Drosophila patched gene in Caucasian and African-American nevoid basal cell carcinoma syndrome patients. Cancer Res 56: 4599-4601, 1996.

17. Tostar U, Malm CJ, Meis-Kindblom JM, Toftgård R and Undén AB: Deregulation of the hedgehog signalling pathway: A possible role for the PTCH and SUFU genes in human rhabdomyoma and rhabdomyosarcoma development. J Pathol 208: 17-25, 2006.

18. Xie J, Johnson RL, Zhang X, Bare JW, Waldman FM, Cogen PH, Menon AG, Warren RS, Chen LC, Scott MP and Epstein EH Jr: Mutations of the PATCHED gene in several types of sporadic extracutaneous tumors. Cancer Res 57: 2369-2372, 1997.

19. Ruiz i Altaba A: Gli proteins encode context-dependent positive and negative functions: Implications for development and disease. Development 126: 3205-3216, 1999.

20. Dahmane N, Lee J, Robins P, Heller P and Ruiz i Altaba A: Activation of the transcription factor Glil and the Sonic hedgehog signalling pathway in skin tumours. Nature 389: 876-881, 1997.

21. Mori Y, Okumura T, Tsunoda S, Sakai Y and Shimada Y: Gli-1 expression is associated with lymph node metastasis and tumor progression in esophageal squamous cell carcinoma. Oncology 70: 378-389, 2006.

22. Schneider S, Thurnher D, Kloimstein P, Leitner V, Petzelbauer P, Pammer J, Brunner M and Erovic BM: Expression of the Sonic hedgehog pathway in squamous cell carcinoma of the skin and the mucosa of the head and neck. Head Neck 33: 244-250, 2011.

23. Wicking $\mathrm{C}$ and McGlinn $\mathrm{E}$ : The role of hedgehog signalling in tumorigenesis. Cancer Lett 173: 1-7, 2001.

24. Tojo M, Mori T, Kiyosawa H, Honma Y, Tanno Y, Kanazawa KY, Yokoya S, Kaneko F and Wanaka A: Expression of sonic hedgehog signal transducers, patched and smoothened, in human basal cell carcinoma. Pathol Int 49: 687-694, 1999. 
25. Kim MY, Park HJ, Baek SC, Byun DG and Houh D: Mutations of the p53 and PTCH gene in basal cell carcinomas: UV mutation signature and strand bias. J Dermatol Sci 29: 1-9, 2002.

26. De Gruijl FR, Van Kranen HJ and Mullenders LH: UV-induces DNA damage, repair, mutations and oncogenic pathways in skin cancer. J Photochem Photobiol B 63: 19-27, 2001.

27. Holikova Z, Massi D, Lotti T and Hercogová J: Insight into the pathogenesis of sporadic basal cell carcinoma. Int J Dermatol 43 865-869, 2004

28. Green J,Leigh IM, Poulsom R and Quinn AG: Basal cell carcinoma development is associated with induction of the expression of the transcription factor Gli-1. Br J Dermatol 139: 911-915, 1998.

29. Lupi O: Correlations between the sonic hedgehog pathway and basal cell carcinoma. Int J Dermatol 46: 1113-1117, 2007.

30. Xuan YH, Li GL, Jiang HY and Lin ZH: Relationship between hedgehog signaling pathway molecules and HPV16 infection in uterine cervical cancers. Zhonghua Bing Li Xue Za Zhi 38: 178-182, 2009 (In Chinese).
31. Xuan YH, Jung HS, Choi YL, Shin YK, Kim HJ, Kim KH, Kim WJ, Lee YJ and Kim SH: Enhanced expression of hedgehog signaling molecules in squamous cell carcinoma of uterine cervix and its precursor lesions. Mod Pathol 19: 1139-1147, 2006.

32. Cavicchioli Buim ME, Gurgel CA, Gonçalves Ramos EA, Lourenço SV and Soares FA: Activation of sonic hedgehog signaling in oral squamous cell carcinomas: A preliminary study. Hum Pathol 42: 1484-1490, 2011

33. Nishimaki H, Kasai K, Kozaki Ki, Takeo T, Ikeda H, Saga S, Nitta $\mathrm{M}$ and Itoh $\mathrm{G}$ : A role of activated Sonic hedgehog signaling for the cellular proliferation of oral squamous cell carcinoma cell line. Biochem Biophys Res Commun 314: 313-320, 2004. 